\title{
Erratum to: Twelve weeks of soccer-specific training: effects on mucosal immunity, salivary alpha-amylase and body composition in male African youths
}

\author{
Dorota E. Starzak ${ }^{1}$ - Kristen F. Konkol ${ }^{2}$ - Andrew J. McKune ${ }^{1,3}$
}

Published online: 18 March 2016

(C) Springer-Verlag Italia 2016

\section{Erratum to: Sport Sci Health}

DOI 10.1007/s11332-016-0263-3

Unfortunately, the corresponding author first and surname have switched and wrongly published in the original article. The correct name should read as follows:

Dorota E. Starzak

The online version of the original article can be found under doi:10.1007/s11332-016-0263-3.

\section{Dorota E. Starzak}

starzakdorota@gmail.com

1 Discipline of Biokinetics, Exercise and Leisure Sciences, School of Health Sciences, University of KwaZulu-Natal, Durban, KwaZulu-Natal, South Africa

2 Department of Human Performance, Minnesota State University, College of Allied Health and Nursing, Minnesota, USA

3 Discipline of Sport and Exercise Science, Faculty of Health, UC-Research Institute for Sport and Exercise, University of Canberra, Bruce, Act, Australia 